\section{Fruit Quality, Antioxidant Capacity, Related Genes, and Enzyme Activities in Strawberry (Fragaria Xananassa) Grown under Colored Plastic Films}

\author{
Lixiang Miao, Yuchao Zhang, Xiaofang Yang, Jinping Xiao, \\ and Huiqin Zhang \\ Institute of Horticulture, Zhejiang Academy of Agricultural Sciences, \\ Hangzhou 310021, Zhejiang, China \\ Ming Jiang \\ College of Life Science, Taizhou University, Linhai 317000, Zhejiang, China
}

Zuofa Zhang, Yuezhi Wang, and Guihua Jiang ${ }^{1}$

Institute of Horticulture, Zhejiang Academy of Agricultural Sciences, Hangzhou 310021, Zhejiang, China

Additional index words. sugar, organic acid, anthocyanin, shikimic acid, MYB10

\begin{abstract}
The influence of colored plastic films (red, yellow, green, blue, and white) on fruit quality, antioxidant capacity, and gene transcripts was studied in greenhousegrown strawberries. Fruits grown under white plastic film were used as the controls. Results indicated that there was no difference in single fruit weight due to colored plastic films in the present study. The colored plastic films had significant effects on sugar and organic acid content. The content of total sugar (SUG) was increased by $10.39 \%$ and total organic acid (ACID) was decreased by $16.58 \%$ in fruit grown under blue plastic film compared with the controls. Fruit grown under blue plastic film had significantly higher SUG content and lower ACID content than fruit subjected to yellow and green plastic films and had the highest SUG/ACID ratio of 11.46. Colored plastic films had significant effects on bioactive compound (anthocyanin, flavonoid, phenolic) content and antioxidant capacity. The highest level of bioactive compound content was detected under red plastic film. The content of total phenolics, total flavonoids, and total anthocyanin (TAC) in fruits grown under red plastic film was respectively $23.10 \%, 25.37 \%$, and $74.11 \%$ higher than that of the fruits grown under the control. The antioxidant capacities were highest in fruits grown under red plastic film. Fruits grown under red and yellow films had higher sucrose phosphate synthase (SPS) and sucrose synthase (SS) activity than those fruit covered with green, blue, and white plastic films at whole fruit development stages. Acid invertase (AI) activity was high in fruit grown under green plastic film and declined during development. Blue plastic film had mainly increased the FaSPS and $F a A I$ transcript at the green stage, and decreased the expression of $F a S S$. It is proposed that colored plastic films can regulate the expression of genes involved in the flavonoid biosynthesis pathway, especially $\mathrm{FaPAL}, \mathrm{FaF} 3 \mathrm{H}, \mathrm{FaFGT}$, and $\mathrm{FaMYB10}$, at half-red and red stages.
\end{abstract}

Strawberries are widely consumed as fresh, frozen, and processed products, with consumption of fresh strawberries being more prevalent than frozen berries (Basu et al., 2014). In addition to basic nutrition (sugars, organic acids, carotenoids, and vitamins),

Received for publication 16 May 2017. Accepted for publication 26 July 2017.

This study was supported by the National Natural Science Foundation of China (31201613), the Zhejiang Provincial Natural Science Foundation of China (LY16C150004), the Young Talent Training Program of Zhejiang Academy of Agricultural Sciences (2015R05R08E01), and the Science and Technology Project of Zhejiang Province (2016C02052-8).

${ }^{1}$ Corresponding author. E-mail: jgh2004267@ sina.cn. strawberry fruits also contain diverse nonnutrient molecules, such as ellagic acid, anthocyanins, quercetin, and catechin. Phenolic compounds are powerful free radical scavengers and exhibit strong antioxidant capacity. Antioxidant and bioactive compounds play important pharmacological roles against various human diseases, such as cardiovascular disease, cancer, inflammation, and allergies (Giampieri et al., 2014). Because of its antioxidant, anti-inflammatory, antihyperlipidemic, antihypertensive, and antiproliferative effects, strawberry fruit is considered a functional food (Giampieri et al., 2014). These health effects are attributed to the synergistic effects of nutrients and phytochemicals in strawberries (Basu et al., 2014). Therefore, it is important to study the regulation of strawberry fruit quality.
Light is an important factor in plant production. A phytochrome system was used by plants to perceive intensity, duration, and spectrum of environmental light to adjust their physiology. Photoselective plastic films, bagging, mulch, coating, or netting can be used to alter light. Far red (FR) and red lights (R), and the ratio of $\mathrm{FR} / \mathrm{R}$ photon can be significantly affected by these applications, which might act through the natural phytochrome system to activate related gene expression and enzyme, and to influence physiological and biochemical responses (Hemming, 2009). Physiological and biochemical characteristics, yield and quality of products can be affected by the changed light environment during plant growth and development stages (Kasperbauer et al., 2001).

Preharvest bagging is an effective physical protection technique widely used in fruit production (e.g., peach, apple, pear, and loquat) in Japan, Australia, China, and the United States. Extensive research has been conducted to determine the effects of fruit bagging on fruit growth, development and quality, antioxidant activities, pest and disease control, and pesticide residues (Sharma et al., 2014). The primary benefits of bagging include improving fruit quality and fruit coloration, excluding pests, and reducing pesticide residues and physical damage (Sharma et al., 2014; Xu et al., 2010). However, there have been contradictory reports on the effects of preharvest fruit bagging on fruit size and weight, ripening, maturity, skin color development, mineral content, and fruit quality (including titratable acidity, the content of total soluble solids, soluble sugars, and organic acid) (Amarante et al., 2002; Hudina and Stampar, 2011). For instance, paper bags reduced the fruit weight of 'Conference' pears (Hudina and Stampar, 2011), whereas using microperforated polyethylene bags for 'Doyenne $\mathrm{du}$ Comice' did not affect fruit size and weight (Amarante et al., 2002). Nonbagged fruits and fruits bagged twice had higher soluble solids than fruits bagged once, and there were no differences in titratable acidity (Lin et al., 2012). These differences may be due to the types of bag used, the stage of fruit development when bagged, the dates of bagging and bag removal, and/or fruit- and cultivar-specific responses (Sharma et al., 2014). Bagging is an effective physical protection technique used for reducing pesticide residues and affecting fruit quality. However, because of its continuous bloom and fruit set habits, strawberry fruit is not suitable for bagging.

A common and conventional production method for strawberries is the annual hill system, which consists of raised beds covered with plastic mulch, mainly black, clear, and white or white-on-black polyethylene. Other colors of mulch are also used in strawberry cultivation. Colored plastic mulches could affect strawberry fruit quality (Casierra-Posada et al., 2011; Kasperbauer et al., 2001; Shiukhy et al., 2015), weight (Casierra-Posada et al., 2011), and bioactive compound content (Shiukhy et al., 2015) by altering the thermal 
and radiation environment of strawberry. Ascorbic acid and sugar contents of fruits were highest when the strawberry plants were grown under blue plastic film (Xu et al., 2007). In contrast to this, sucrose concentration, dry matter, and ash content of the fruits grown under different new photoselective greenhouse films had no significant differences in the experiment of Hemming et al. (2006). Fruits grown under blue plastic films were found to be slightly more acidic than fruits grown under the control, whereas fruits grown under red plastic films were found to be less acidic (Hemming et al., 2006). According to the data of Xu et al. (2007), fruit surface color was the reddest under red plastic film. Fruits grown under blue fluorescent and red plastic films were slightly and apparently brighter than fruits grown under white plastic film (Hemming et al., 2006). In addition, blue light irradiation can maintain postharvest strawberry quality and improve nutritional value of fruit through the enhancement of their antioxidant systems and free radical-scavenging capabilities (Xu et al., 2014). The reasons for these contradictory results may be due to the strawberry cultivar, the kinds of covered plastic films, and the mulching patterns.

Colored plastic films were only used to cover strawberry inflorescences on the same side of the raised bed. This application can provide very little contact with pesticide. It has been reported that the content of anthocyanin, the activities of the related enzymes, and the transcripts of the flavonoid gene in strawberry fruit could be affected by colored plastic films (Miao et al., 2016). Fruits grown under red and yellow plastic films can enhance the anthocyanin content in developing strawberry fruit (Miao et al., 2016). However, whether this application affects strawberry fruit quality is still unknown.

The relative expression level of genes recognized as having major roles in the biosynthesis of sugar, organic acids, and bioactive compounds, such as SPS, SS, and AI, phenylalanine ammonia-lyase (PAL), flavonoid 3-hydroxylase $(\mathrm{F} 3 \mathrm{H})$, flavonol synthase (FLS), flavonoid glucosyltransferase (FGT) and dihydroflavonol-4-reductase (DFR), and MYB10, was determined using real-time quantitative polymerase chain reaction (qPCR) (Basson et al., 2010; Jaakola, 2013; Tian et al., 2012). In this article, the contents of sugar, organic acids, and bioactive compounds, which are involved in fruits quality, had been measured in fruits grown under colored plastic films. Antioxidant capacity, enzyme activity, and related gene expression were also determined. The purpose of this study was to explore not only the changes in the fruit quality but also the antioxidant capacity in strawberry fruit grown under colored plastic films.

\section{Materials and Methods}

Standards and chemicals. The chemicals 2,2' -azinobis-(3-ethylbenzothiazoline-6sulfonate) (ABTS), 1,1-diphenyl-2-picrylhydrazyl (DPPH), 2,4,6-tri(2-pyridyl)-s-triazine (TPTZ),
pelargonidin-3-O-glucoside (Pg3G), 6-hydroxy2,5,7,8-tetramethylchroman-2-carboxylic acid (Trolox), and rutin were purchased from Sigma-Aldrich (Shanghai, China). All other chemicals and solvents were of analytical reagent grade and were purchased from Sangon Biotech Co., Ltd (Shanghai, China).

Plant materials and experimental treatments. Strawberry (Fragaria $\times$ ananassa Duch. cv. Yueli) plantlets were planted in two plastic greenhouses in Sept. 2013 in Haining $\left(120^{\circ} 24^{\prime} \mathrm{E}, 30^{\circ} 26^{\prime} \mathrm{N}\right)$, Zhejiang province, China. Each plastic greenhouse measured $8 \mathrm{~m}$ in width and $75 \mathrm{~m}$ in length, with an orientation of north to south, and had eight raised beds. The strawberry raised beds measured $60 \mathrm{~cm}$ in width and $30 \mathrm{~cm}$ in height and were mulched with black polyethylene film. Two rows of plants were planted in each raised bed, with a row spacing of $30 \mathrm{~cm}$ and a plant spacing of $20 \mathrm{~cm}$. The soil had a $\mathrm{pH}$ value of 5.56. The levels of organic matter and total nitrogen were $3.27 \%$ and $0.221 \%$, respectively. The available nitrogen, phosphorus, and potassium in the soil were 169 , 88.5 , and $167 \mathrm{mg} \cdot \mathrm{kg}^{-1}$, respectively. Calcium cyanamide $\left(450 \mathrm{~kg} \cdot \mathrm{ha}^{-1}\right)$ was used for soil disinfection and sterilization before the strawberry plantlets were planted. The drip irrigation system used irrigation tapes with diameters of $40 \mathrm{~mm}$ placed under the black polyethylene mulch with emitters separated by $20 \mathrm{~cm}$, close to the strawberry plants. A water-soluble fertilizer (12-2-14 NPK) was used in this study. The major components in the fertilizer were $\mathrm{NO}_{3}-\mathrm{N}(11.7 \%), \mathrm{NH}_{4}-\mathrm{N}$ $(0.3 \%), \mathrm{P}_{2} \mathrm{O}_{5}(2 \%), \mathrm{K}_{2} \mathrm{O}(14 \%)$, EDTA-Fe $(0.05 \%)$, EDTA-Mn $(0.05 \%)$, EDTA-Zn $(0.05 \%), \mathrm{B}(0.05 \%), \mathrm{Ca}(6 \%)$, and $\mathrm{Mg}$ (3\%). The 12-2-14 fertilizer was applied with $240 \mathrm{mg} \cdot \mathrm{kg}^{-1} \mathrm{~N}$ from fruit setting to maturity, and the frequency of application was once for every single watering process. Procymidone (3\%) and chlorothalonil (12\%) were used to prevent the occurrence of gray mold at the flowering stage.

Seven days after full bloom of the first inflorescence, the two secondary fruits from the first strawberry inflorescence in the east rows were covered with colored plastic films (red, yellow, green, blue, and white) from 12 Dec. 2013 to 14 Jan. 2014, and other flowers and fruits were removed (Anttonen et al., 2006). Raised beds were mulched with black polyethylene film, and the selected strawberry fruits were hung on both sides of the raised bed. Wire brackets were fixed between the upper and lower side of the raised bed. Colored plastic films were covered on the wire brackets (Fig. 1). Fruits grown under white plastic film served as controls. The experiment was conducted in a randomized block design with three replications. Each experimental unit consisted of 30 plants covered by plastic film of the same color in a plastic greenhouse. The colored plastic films (Weikang colored film factory, Shanghai, China) were $0.03 \mathrm{~mm}$ thick. With the aid of an LI-1800 portable spectroradiometer (LI-COR), the radiation spectrum of different colored plastic films was evaluated. The irradiances (300-1100 nm) observed in red, yellow, green, blue, and white plastic films were $155.8,153.7,151.1,155.3$, and 157.2 $\mathrm{W} \cdot \mathrm{m}^{-2}$, respectively. The percentage of the blue $(400-510 \mathrm{~nm})$ irradiance spectrum in the overall radiant energy of the red, yellow, green, blue, and white plastic films was $1.82 \%, 8.53 \%, 11.03 \%, 18.98 \%$, and $8.02 \%$, respectively. The percentage of the red irradiance $(610-710 \mathrm{~nm})$ spectrum in the overall radiant energy of red, yellow, green, blue, and white plastic films was $27.63 \%, 21.27 \%$, $9.63 \%, 12.72 \%$, and $21.65 \%$, respectively. MIK-ETH100 automatic recorders (Hang Zhou Meacon Automation Technology Co., Ltd, Hangzhou, China) were used to record the temperature and relative humidity values under the colored plastic films. Ripening fruits from each replication were picked and weighed using an electronic balance. Ten strawberries from each replication were sliced into small segments, and the strawberry slices were ground into a powder with the help of liquid nitrogen.

The analysis of the content of sugars and organic acids. Two grams of the strawberry powder was mixed with $10 \mathrm{~mL}$ of $90 \%(\mathrm{v} / \mathrm{v})$ ethanol/water and kept at $90{ }^{\circ} \mathrm{C}$ for $30 \mathrm{~min}$. The extract was passed through two layers of qualitative filter paper (round $12.5 \mathrm{~cm}$, Sangon Biotech Co., Ltd.), and the filtrate was collected in a new centrifuge tube. A $3-\mathrm{mL}$ sample of the filtrate was treated in a Labconco CentriVap Concentrator (Labconco Corporation, Kansas City, KS) at $60{ }^{\circ} \mathrm{C}$ for $10 \mathrm{~h}$. One milliliter of sterile water was added to thoroughly dissolve the residue. Then, the solute was transferred to a Sep-Pak $\mathrm{C}_{18}$ column (Waters Oasis HLB column, Waters Corporation, Milford, MA) to remove the pigments, phenolic lipids, and insoluble substances. The final filtrate was stored at $-20{ }^{\circ} \mathrm{C}$ for sugar and organic acid analyses.

The HPLC system consisted of a Waters Alliance Separations Module (model e2695) and a 2414 Refractive Index Detector (for sugar analysis) or a 2998 PDA detector (for organic acid analysis) controlled by the Breeze software. The separation column used for sugar analysis was a Waters SugarPak1 (4.6 $\times 250 \mathrm{~mm}, 5 \mu \mathrm{m}$, Waters Corporation). Glucose, fructose, sucrose, and uridine diphosphate galactose (UDP-galactose) were detected. The quantity and type of sugar were determined as described by Xu et al. (2010).

Organic acids were analyzed with a 2998 PDA Detector set at $210 \mathrm{~nm}$ using an X-bridge C18 column $(4.6 \times 250 \mathrm{~mm}, 5 \mu \mathrm{m}$, Waters Corporation) operated at $30{ }^{\circ} \mathrm{C}$. The elution solvent was $0.01 \mathrm{~mol} \cdot \mathrm{L}^{-1}$ sulfuric acid (pH 2.6) passed at a rate of $0.5 \mathrm{~mL} \cdot \mathrm{min}^{-1}$. The quantity and type of organic acids were determined as described by Shui and Leong (2002).

Measurement of bioactive compound content and antioxidant capacity. TAC was measured using a spectrophotometer (U-0080D, Hitachi, Japan) (Medina-Puche et al., 2014). To analyze the total phenolics, total flavonoids, and antioxidant capacity, the fruits were extracted with methanol using the method described by Swain and Hillis (1959), with 
some modifications. Two grams of strawberry fruit powder was homogenized with $10 \mathrm{~mL}$ of methanol. The homogenates were kept at $4{ }^{\circ} \mathrm{C}$ for $12 \mathrm{~h}$ and then centrifuged at $15,000 \mathrm{rpm}$ for $20 \mathrm{~min}$. The supernatants were then collected, and extraction of the residue was repeated using the same conditions. The two supernatants in methanol were combined, divided into two equal aliquots and then stored at $-20{ }^{\circ} \mathrm{C}$ until analysis. The total phenolic content was quantified using the Folin-Ciocalteu method (Singleton and Rossi, 1965). The flavonoid content of different fractions was measured using a colorimetric assay developedby Jia et al. (1999). To estimate the antioxidant capacities of the fruit extracts, the DPPH, ABTS, and ferric reducing/antioxidant power (FRAP) assays were performed as described by $\mathrm{Xu}$ et al. (2010).

Enzyme extraction and assay. SPS, SS, and $\mathrm{AI}$ were recognized as having major roles in sugar and acid metabolism in strawberry fruits (Basson et al., 2010; Tian et al., 2012). SPS is a key enzyme in the synthesis of sucrose, and SS is a key enzyme catalyzing both the synthesis and hydrolysis of sucrose (Basson et al., 2010). AI hydrolyzes sucrose to its constituent hexoses (glucose and fructose) and regulates the accumulation of sucrose (Tian et al., 2012). Therefore, these enzymes were chosen to evaluate the effects of colored plastic films on sugar and acid accumulation in this study. The enzyme extractions used for the SPS, SS, and AI assays were described by Mi et al. (2011). The protocols for the determination of activities of SPS, SS, and AI were described by Miron and Schaffer (1991).

Gene expression. The total RNA was extracted using the cetyltrimethylammonium bromide method (Chang et al., 2007). TransScript ${ }^{\circledR}$ One-Step gDNA Removal and cDNA Synthesis SuperMix kits (TransGen Biotech, Beijing, China) were used to synthesize first-strand cDNA. Real-time qPCR was used to determine the levels of these genes during strawberry fruit development after being covered with colored plastic films. The qPCR primers were designed with Primer 3 software (http://primer3.sourceforge.net/, Table 1). The qPCR was performed on a LightCycler ${ }^{\circledR} 96$ real-time PCR instrument (Roche, Switzerland) using the SYBR FastStart Essential DNA Green Master Mix (Roche, Switzerland). FaACTIN presents consistent transcript level throughout the strawberry fruits and leaves (Amil-Ruiz et al., 2013; Lin-Wang et al., 2010). Therefore, we selected this gene as a reference gene. The qPCR reactions were normalized using the $\mathrm{C}_{\mathrm{T}}$ value corresponding to FaACTIN through the $2^{-\triangle C T}$ method (Livak and Schmittgen, 2001). All analyses were performed three times using three biological replications.

Statistical analysis. All results were reported as the mean \pm SE. The significance of the results and differences were analyzed using Data Processes System software package (Tang and Zhang, 2012) and evaluated by the one-way analysis of variance followed by Tukey's multiple comparisons test at $P<$ 0.05 . Pearson correlations were used to determine the relationship between bioactive compounds and antioxidant capacity.

\section{Results and Discussion}

Change of single fruit weight, temperature, and relative humidity. There was no significant difference in single fruit weight grown under colored plastic films in the present study (Table 2). Red, yellow, and green plastic films resulted in the highest mean temperature, and no statistically significant difference was found among them. The relative humidity surrounding the fruits grown under colored plastic films was lower than that surrounding the controls. Fruits grown under red plastic film first arrived at the ripening stage $(31.2 \mathrm{~d})$, followed by yellow plastic film (32.5 d), white plastic film (36.4 d), green plastic film (39.8 d), and finally blue plastic film $(43.7 \mathrm{~d})$.

In contrast to our data, Hemming et al. (2006) demonstrated that red plastic film led to a higher mean fruit weight than blue plastic films. This may be caused by different

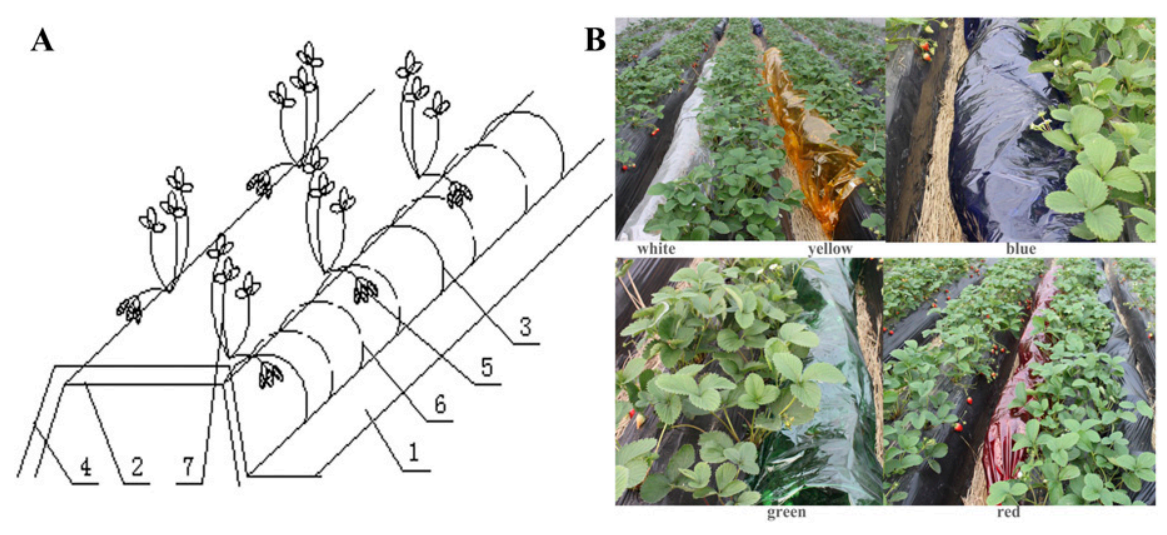

Fig. 1. Fruits grown under colored plastic films. (A) Sketch of fruits grown under colored plastic films; 1 : furrow; 2: raised bed; 3: wire bracket; 4: black polyethylene film; 5 : strawberry fruits; 6: colored plastic film; 7: strawberry plant. (B) Fruits grown under colored plastic films in a greenhouse.

Table 1. Primers used in quantitative polymerase chain reaction.

\begin{tabular}{|c|c|c|c|}
\hline Gene & Accession no. & Primer sequence $\left(5^{\prime}\right.$ to $\left.3^{\prime}\right)$ (forward/reverse) & Product size $(\mathrm{bp})$ \\
\hline \multirow[t]{2}{*}{$\overline{F a A C T I N}$} & AB116565 & GCTAATCGTGAGAAGATGAC & 119 \\
\hline & & AGCACAATACCAGTAGTACG & \\
\hline \multirow[t]{2}{*}{ FaSPS } & XM_004287224 & AAGACCATCATCCTACTCCT & 204 \\
\hline & & GAGAGAAGAACAGAAGCACT & \\
\hline \multirow[t]{2}{*}{ FaSS } & XM_004287496 & TTTGGTCTGGAGTGAAGTCT & 277 \\
\hline & & TCCAACATAGTGAGCATACC & \\
\hline \multirow[t]{2}{*}{ FaAI } & XM_004298613 & TTGATGATGATAGGAATGATTAC & 139 \\
\hline & & AAGGTCTTGGAAGCATAG & \\
\hline \multirow[t]{2}{*}{ FaPAL } & HM641823 & CAACCAAGATGTCAACTCCT & 271 \\
\hline & & TCAATGGATAGGTAGCAAGG & \\
\hline \multirow[t]{2}{*}{$\mathrm{FaF3H}$} & AY691918 & GACCTACTTCTCATACCCGG & 215 \\
\hline & & CGTTTGAGTCCGAGAGTGAG & \\
\hline \multirow[t]{2}{*}{ FaDFR } & AY780884 & GAGAACGAAGTGATAAAGCC & 131 \\
\hline & & AAACACAACATCGCTCCAGT & \\
\hline \multirow[t]{2}{*}{$F a F G T$} & AY695815 & CGTCCGTGGTCTATGTGAGT & 303 \\
\hline & & ACATCCTCAACCATCCTCGC & \\
\hline \multirow[t]{2}{*}{ FaFLS } & DQ087252 & CTTGCTCTTGGTGTGGTTGC & 231 \\
\hline & & GCCCTATTACTTGGTCTGCC & \\
\hline \multirow[t]{2}{*}{ FaMYB10 } & EU155162 & GCTTCTGAAACAGTTCATCG & 247 \\
\hline & & CTTCACATCATTGGCAGTTC & \\
\hline
\end{tabular}

$A C T I N=$ actin; $S P S=$ sucrose phosphate synthase; $S S=$ sucrose synthase; $A I=$ acid invertase; $P A L=$ phenylalanine ammonia-lyase; $F 3 H=$ flavonoid 3-hydroxylase; $D F R=$ dihydroflavonol-4-reductase; $F G T=$ flavonoid glucosyltransferase $F L S=$ flavonol synthase; $M Y B 10=\mathrm{v}$-myb avian myeloblastosis viral oncogene homolog 10 .

Table 2. Mean fruit weight, temperature, and relative humidity under the colored plastic films.

\begin{tabular}{lccc}
\hline Colored plastic film & Fruit wt $(\mathrm{g})$ & Temp $\left({ }^{\circ} \mathrm{C}\right)$ & Humidity $(\%)$ \\
\hline Red & $24.71 \pm 1.34 \mathrm{a}$ & $10.0 \pm 0.2 \mathrm{a}$ & $82.4 \pm 3.15 \mathrm{~b}$ \\
Yellow & $24.93 \pm 1.37 \mathrm{a}$ & $9.6 \pm 0.12 \mathrm{a}$ & $85.7 \pm 2.56 \mathrm{~b}$ \\
Green & $25.34 \pm 1.25 \mathrm{a}$ & $9.7 \pm 0.1 \mathrm{a}$ & $82.4 \pm 2.12 \mathrm{~b}$ \\
Blue & $25.53 \pm 1.95 \mathrm{a}$ & $9.4 \pm 0.1 \mathrm{~b}$ & $87.7 \pm 1.47 \mathrm{~b}$ \\
White (control) & $25.10 \pm 1.28 \mathrm{a}$ & $9.1 \pm 0.1 \mathrm{c}$ & $94.9 \pm 2.35 \mathrm{a}$ \\
\hline
\end{tabular}

Values in the same column followed by a different small letter are significantly different $(P<0.05)$. 
experimental designs. Only the two secondary fruits from the first strawberry inflorescence were covered with colored plastic films in our experiment. The first and other fruits in the inflorescence had been eliminated. Hence, these fruits selected for testing were very identical. However, the whole plant with all the fruits were grown under colored plastic films in the experiments of Hemming et al. (2006). The $\mathrm{R} / \mathrm{FR}$ ratio may have more effect on plants than on fruits (Hemming et al., 2006). In addition, red, blue, and white photoselective nets significantly increased the size and weight of the single blueberry compared with berries grown in open field (Zoratti et al., 2015).

Effect of colored plastic films on the sugar content in ripened strawberry fruit. The mean content of individual sugars is shown in Table 3. Sucrose was the primary sugar in 'Yueli', as in most strawberry cultivars, although fructose and glucose are the primary sugars in some strawberry cultivars (Mahmood et al., 2012). Compared with the controls, the sucrose content increased when blue plastic film was used $(45.20 \%$ to $50.36 \%$ ) but decreased with red (to $41.69 \%$ ) and green (to $39.76 \%$ ) plastic films. Fructose and glucose content also increased under blue plastic film but declined when red plastic film was used. Only yellow plastic film resulted in a UDP-galactose content lower than that of the controls.

UDP-galactose, which accumulates in strawberry leaves, has previously been detected in the ripened fruits (Isherwood and Selvendran, 1970). Cyanidin 3-galactoside, a predominant anthocyanin in apple skin, is synthesized from cyanidin and UDPgalactose by UDP-galactose: flavonoid 3$O$-galactosyltransferase (UFGalT) activity (Ban et al., 2009). UDP-sugars are substrates for UFGalT in anthocyanin biosynthesis in some strawberry cultivars, such as 'Camarosa' and 'Tudnew' (Silva et al., 2007). However, studies on strawberries have focused on the anthocyanin biosynthetic pathway and have no information on UDP-sugars.

Fruits grown under blue plastic film had significantly more SUG than those grown under other plastic films, corresponding to a $10.39 \%$ increase compared with the controls. The SUG content resulting from the usage of red, yellow, or green plastic films exhibited no significant differences. The SUG in fruits grown under red plastic film was $7.70 \%$ lower than that in fruits grown under the control. Hence, blue plastic film might be useful as a supplemental cultivation practice to enhance the SUG in strawberry fruit. However, higher concentrations of sucrose, fructose, glucose, and SUG were evident in strawberries grown on a raised bed covered with red plastic mulch vs. black mulch (Kasperbauer et al., 2001). The contradictory results may be due to different selected control films. On the contrary, the sucrose concentration among colored plastic films had no significant differences (Hemming et al., 2006).

Effect of colored plastic films on the organic acid content in ripened strawberry fruit. Citric acid comprises the highest proportion of ACID in strawberries, which is consistent with the results of the previous study (Mahmood et al., 2012). Fruits grown under colored plastic films had a significant decrease of citric acid content compared with the controls. Malic, oxalic, and shikimic acids also can be detected in strawberry fruits. Malic acid and ACID in fruits grown under the red, green, and blue plastic films were significantly lower than those in fruits grown under the control and the yellow plastic film (Table 4). The citric acid content decreased with all the colored plastic films compared with that of the controls. Fruits grown under the colored plastic films (red, blue, and green) had less malic acid and ACID than the controls. The yellow and green plastic films increased the oxalic acid content from $1.34 \mathrm{mg} \cdot \mathrm{g}^{-1} \mathrm{FW}$ to $2.25 \mathrm{mg} \cdot \mathrm{g}^{-1}$ FW and to $1.58 \mathrm{mg} \cdot \mathrm{g}^{-1} \mathrm{FW}$, respectively (Table 4).

Shikimic acid is enriched in star anise fruits and commonly found in edible fruits, such as pears, blackberries, cherries, bananas, and strawberries (Hulme, 1958). Shikimic acid may not have a direct effect on the quality and flavor of fruits, and it principally serves as an important link between the aliphatic and aromatic metabolisms of plants (Ding et al., 2007). Shikimic acid can also affect the accumulation of anthocyanin in fruits. Compared with the controls, the fruits grown under red, green, and blue plastic films had a decreased content of shikimic acid. Shikimic acid is a key intermediate product in the shikimic acid metabolism pathway, which can control the production of phenylalanine (Mobin et al., 2015). Decrease in shikimic acid content had the ability to strengthen the biosynthesis of phenylalanine and increase the content of anthocyanins.

The flavor quality of strawberry fruits is largely determined by the SUG/ACID ratio (Kasperbauer et al., 2001). Because strawberries are widely consumed as fresh fruits in Asia, especially in China, the SUG/ACID ratio is an important index of flavor. Table 4 shows that the fruits grown under blue plastic film had the highest SUG/ACID ratio because they had the highest sugar content and lowest acid content. The higher SUG/ACID ratio under the blue plastic film is also consistent with the controlled environment responses of plant parts to low R/FR photon ratios (Samuolienè et al., 2010). The blue plastic film used in the present study reflected less red and far-red lights with a lower R/FR photon ratio than the control plastic film. It is apparent that the reflected red and far red lights were involved in modifying chemical pathways in which sugar and organic acid were included. Sugar and organic acid contents of ripe fruits grown under blue plastic film were significantly higher than those of the controls. In agreement with Kasperbauer et al. (2001), the positive influence of the red plastic film treatment on the SUG/ACID ratio was observed. This process requires the participation of sugar accumulationrelated enzymes and genes. In addition, the fruits grown under red and green plastic films had higher SUG/ACID ratios compared with h.

Effect of colored plastic films on the expression of genes FaSPS, FaSS, and FaAI, and related enzyme activity. SPS, SS, and $\mathrm{AI}$ were recognized as having major roles

Table 3. Mean content of individual sugars and total sugar in ripe strawberry fruit grown under colored plastic films.

\begin{tabular}{|c|c|c|c|c|c|}
\hline Colored plastic film & Sucrose $\left(\mathrm{mg} \cdot \mathrm{g}^{-1} \mathrm{FW}\right)$ & Glucose $\left(\mathrm{mg} \cdot \mathrm{g}^{-1} \mathrm{FW}\right)$ & Fructose $\left(\mathrm{mg} \cdot \mathrm{g}^{-1} \mathrm{FW}\right)$ & UDP-galactose $\left(\mathrm{mg} \cdot \mathrm{g}^{-1} \mathrm{FW}\right)$ & SUG $\left(\mathrm{mg} \cdot \mathrm{g}^{-1} \mathrm{FW}\right)$ \\
\hline Red & $41.69 \pm 0.11 \mathrm{~cd}^{\mathrm{z}}$ & $15.28 \pm 0.09 \mathrm{c}$ & $18.99 \pm 0.05 \mathrm{c}$ & $15.15 \pm 0.18 \mathrm{a}$ & $91.11 \pm 0.15 \mathrm{c}$ \\
\hline Yellow & $44.51 \pm 1.69 \mathrm{bc}$ & $17.93 \pm 0.70 \mathrm{~b}$ & $21.83 \pm 0.57 \mathrm{~b}$ & $13.63 \pm 0.89 \mathrm{~b}$ & $97.91 \pm 3.78 \mathrm{bc}$ \\
\hline Green & $39.76 \pm 1.08 \mathrm{~d}$ & $17.12 \pm 0.82 \mathrm{~b}$ & $20.86 \pm 0.77 \mathrm{~b}$ & $15.16 \pm 0.64 \mathrm{a}$ & $92.89 \pm 3.26 \mathrm{bc}$ \\
\hline Blue & $50.36 \pm 2.70 \mathrm{a}$ & $20.24 \pm 1.02 \mathrm{a}$ & $23.51 \pm 1.11 \mathrm{a}$ & $14.87 \pm 0.56 \mathrm{ab}$ & $108.98 \pm 5.27 \mathrm{a}$ \\
\hline White (control) & $45.20 \pm 1.41 \mathrm{~b}$ & $17.35 \pm 0.99 \mathrm{~b}$ & $20.81 \pm 1.01 \mathrm{~b}$ & $15.36 \pm 1.01 \mathrm{a}$ & $98.72 \pm 4.26 \mathrm{~b}$ \\
\hline
\end{tabular}

${ }^{\mathrm{z}}$ Values in the same column followed by the different small letter are significantly different $(P<0.05) . \mathrm{SUG}=$ total sugar.

Table 4. Mean content of individual acids and total organic acids in ripe strawberry fruit grown under colored plastic films.

\begin{tabular}{|c|c|c|c|c|c|c|}
\hline Colored plastic film & $\begin{array}{c}\text { Citric acid } \\
\left(\mathrm{mg} \cdot \mathrm{g}^{-1} \mathrm{FW}\right)\end{array}$ & $\begin{array}{l}\text { Malic acid } \\
\left(\mathrm{mg} \cdot \mathrm{g}^{-1} \mathrm{FW}\right)\end{array}$ & $\begin{array}{l}\text { Oxalic acid } \\
\left(\mathrm{mg} \cdot \mathrm{g}^{-1} \mathrm{FW}\right)\end{array}$ & $\begin{array}{c}\text { Shikimic acid } \\
\left(\mathrm{mg} \cdot \mathrm{g}^{-1} \mathrm{FW}\right)\end{array}$ & $\mathrm{ACID}\left(\mathrm{mg} \cdot \mathrm{g}^{-1} \mathrm{FW}\right)$ & SUG/ACID ratio \\
\hline Red & $6.87 \pm 0.26 \mathrm{c}^{\mathrm{z}}$ & $1.03 \pm 0.05 \mathrm{~b}$ & $1.15 \pm 0.05 \mathrm{~d}$ & $0.021 \pm 0.0021 \mathrm{~b}$ & $9.08 \pm 0.30 \mathrm{~b}$ & $10.05 \pm 0.34 \mathrm{~b}$ \\
\hline Yellow & $7.50 \pm 0.16 b$ & $1.60 \pm 0.07 \mathrm{a}$ & $2.25 \pm 0.04 \mathrm{a}$ & $0.027 \pm 0.0038 \mathrm{a}$ & $11.38 \pm 0.28 \mathrm{a}$ & $8.60 \pm 0.12 \mathrm{c}$ \\
\hline Green & $6.49 \pm 0.08 \mathrm{~d}$ & $1.03 \pm 0.03 \mathrm{~b}$ & $1.58 \pm 0.04 b$ & $0.021 \pm 0.0025 b$ & $9.13 \pm 0.15 b$ & $10.18 \pm 0.20 b$ \\
\hline Blue & $7.51 \pm 0.09 \mathrm{~b}$ & $0.99 \pm 0.013 b$ & $0.99 \pm 0.04 \mathrm{e}$ & $0.019 \pm 0.0002 b$ & $9.51 \pm 0.14 b$ & $11.46 \pm 0.62 \mathrm{a}$ \\
\hline White (control) & $8.49 \pm 0.23 \mathrm{a}$ & $1.54 \pm 0.017 \mathrm{a}$ & $1.34 \pm 0.039 \mathrm{c}$ & $0.029 \pm 0.0036 \mathrm{a}$ & $11.40 \pm 0.27 \mathrm{a}$ & $8.67 \pm 0.33 \mathrm{c}$ \\
\hline
\end{tabular}

${ }^{\mathrm{z}}$ Values in the same column followed by the different small letter are significantly different $(P<0.05)$. ACID $=$ total organic acids; SUG $=$ total sugar. 
in sugar and acid metabolism in strawberries (Basson et al., 2010; Ogiwara et al., 2005). Hence, to explore the mechanisms of sugar metabolism in these fruits grown under colored plastic films, the transcription levels of the sugar and acid accumulation-related genes FaSPS, FaSS, and FaAI were measured using qPCR at green, reddish, half-red, and red stages during strawberry fruit development (Fig. 2). The results showed that the response of FaSPS, FaSS, and FaAI gene expression in strawberry fruit was different in the four development stages when covered with colored plastic films.

Fruits grown under red and blue plastic films had significantly higher FaSPS expression than the controls at the green stage, whereas the yellow and green plastic films resulted in lower expression levels (Fig. 2A). At reddish and half-red stages, the fruits grown under red, yellow, green, and blue plastic films had significantly lower FaSPS expression than the controls. At the mature fruit stage, the fruits covered with red, yellow, and green plastic films had significantly higher FaSPS expression, whereas those grown under blue plastic film had lower FaSPS expression than the controls.
A previous report showed that $F a S S$ plays an important role in the regulation of strawberry fruit ripening (Zhao et al., 2017). In agreement with Zhao et al. (2017), expression of FaSS can be affected by colored plastic films in the present study. At the green stage, the fruits covered with red, yellow, and blue plastic film can decrease the expression of FaSS when compared with the controls (Fig. 2B). The red plastic film resulted in a significantly lower amount of transcripts than those in the controls at the reddish stage. However, at the reddish stage, FaSS expression in the fruits grown under yellow, blue, and green plastic films showed no significant difference when compared with the controls. At the half-red stage, those grown under red, yellow, green, and blue plastic films had significantly higher $\mathrm{FaSS}$ expression than the controls. At the red stage, those grown under colored plastic films had lower FaSS expression than the controls, except with blue plastic film.

The FaAI gene had similar expression patterns in the fruits grown under different plastic films (Fig. 2C). The transcription level of FaAI declined toward maturity (the red stage). Fruits grown under blue plastic film exhibited 2-fold higher expression compared with the controls at the green stage, whereas the other plastic films exhibited $\approx 1.5$-fold higher expression compared with the control. This trend was reversed in the reddish stage. Fruits grown under white plastic film had the highest expression at the reddish stage. At the half-red stages, the fruits grown under red, yellow, green, and blue plastic films showed significantly less expression than the controls, whereas the red plastic film resulted in the highest expression at the red stage.

The photosynthates transported into strawberry fruit are mainly in the form of sucrose. High levels of expression of FaSPS suggest that the loaded hexoses (e.g., glucose and fructose) can be rapidly converted into sucrose, whereas the resynthesized sucrose may be cleaved by FaAI, FaSS, or both (Tian et al., 2012). In the present study, the level of FaSPS transcript was significantly higher in the fruits under other colored plastic films only at the green stage, and FaSS transcripts were most highly expressed in the half-red and red fruits. The blue plastic film had mainly increased the FaSPS transcript at the green stage (more sucrose was accumulated), and decreased the expression of FaSS (little
A

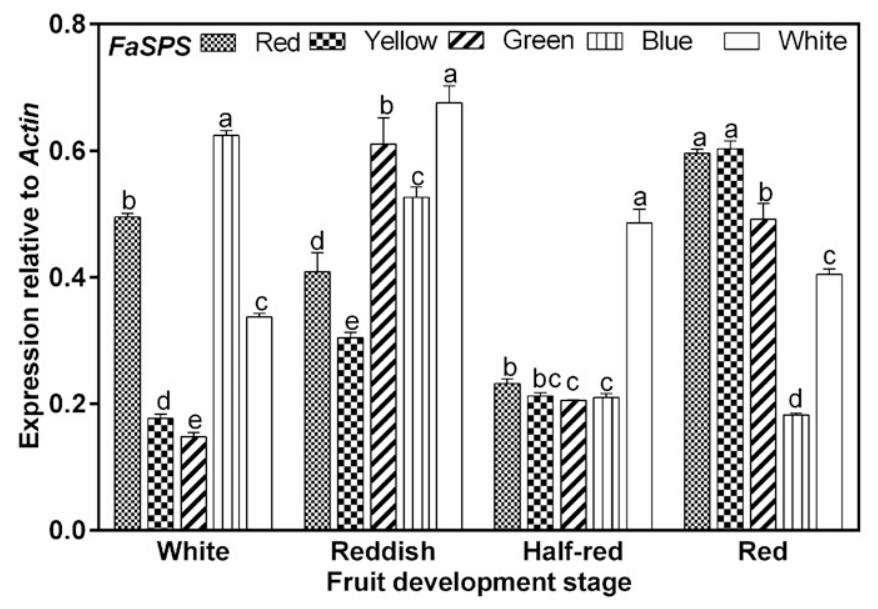

C

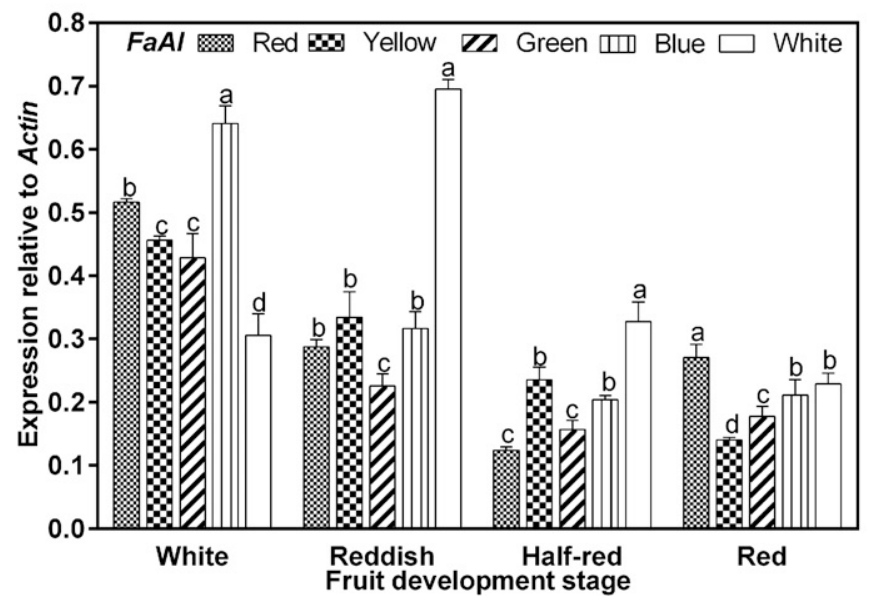

B

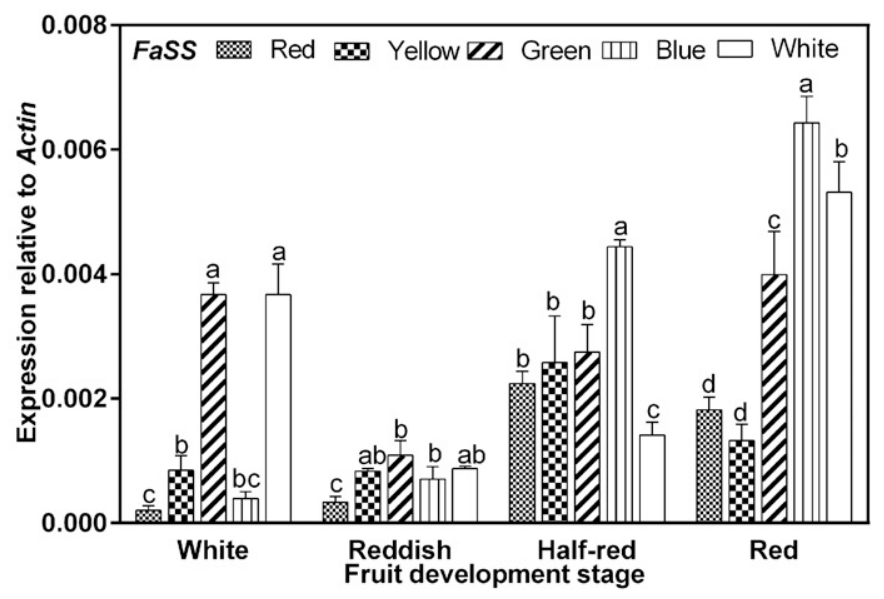

Fig. 2. Effect of colored plastic films on expression of (A) FaSPS, (B) FaSS, and (C) FaAI during strawberry fruit development. Values are the means. Vertical bars represent the SD of the means. Values with different small letter mean significant difference $(P<0.05)$ within a stage, and those with the same letter represent no significant difference $(P>0.05)$. The same was as below. 
sucrose was hydrolyzed). In addition, the fruits grown under blue plastic film had lower content of TAC, which accumulated in ripe strawberry fruit. Therefore, the higher content of sucrose in the fruits grown under blue plastic film may result from long-time maintenance in the green stage. The high level of expression of FaAI means that more glucose and fructose will be synthesized. In the present study, the level of FaAI was higher in the controls only at the green stage (Fig. 2C). Therefore, the higher content of glucose and fructose may be due to the long growth time at the green stage.

SPS and SS activity showed a similar trend for the fruits grown under different colored plastic films (Fig. 3A and B). The highest values of SPS and SS activity were observed at the reddish stage. Fruits grown under red and yellow plastic films had higher SPS or SS activity than those covered with green, blue, and white plastic films at whole fruit development stages. The AI activity was high in the fruit grown under green plastic film and declined during development, as was previously reported (Basson et al., 2010). The fruits grown under colored plastic films had significantly lower activities of AI compared with the controls (Fig. 3C). The lowest AI activity was observed in the fruits grown under blue plastic film at the whole fruit development.

Effect of colored plastic films on the expression of FaPAL, FaF3H, FaFLS, FaFGT, $F a D F R$, and FaMYB10. Flavonoids are the main polyphenol compounds in strawberry fruits, and their biosynthetic pathway has been extensively studied (Lin-Wang et al., 2010; Medina-Puche et al., 2014). To study the effects of colored plastic films on the transcriptional profiles of flavonoid genes using qPCR, the levels of FaPAL, FaF3H, FaFLS, FaFGT, FaDFR, and FaMYB10 gene expression leading to flavonoid biosynthesis in strawberries were investigated from green to red stages (Fig. 4).

Flavonoid biosynthesis uses phenylalanine to produce phenylpropanoids, which are regulated by PAL. The expression of FaPAL used for qPCR in this study is fruit specific and increases during fruit ripening along with anthocyanin accumulation (Pombo et al., 2011). Fruits grown under red plastic film had an increased $F a P A L$ expression level in the green stage compared with the controls, and those grown under green plastic film had a decreased the FaPAL transcript level. The transcript levels of $F a P A L$ in fruits grown under yellow, green, and blue plastic films were lower than those in the controls at the reddish stage. Compared with the fruits grown under the control plastic film, those grown under red and yellow plastic films had FaPAL expression values that were increased by $38.65 \%$ and $34.87 \%$, respectively, at the red stage. When the increased accumulation of total phenolics, total flavonoids, and TAC has been considered in the fruits grown under red plastic film, FaPAL may be regarded as the important factor in this process.

The $\mathrm{F} 3 \mathrm{H}$ enzyme dihydroflavonol products are the substrates of FLS and lead, together with the involvement of several glycosyltransferases, to the production of flavonols. FaF3H, FaFLS, and FaFGT play crucial roles in this process. Increased $\mathrm{FaF} 3 \mathrm{H}$ and $\mathrm{FaFGT}$ gene expression were observed during fruit development. Compared with the controls, the fruits grown under colored plastic films had lower $\mathrm{FaF} 3 \mathrm{H}$ expression at the green (except the blue film) and reddish stages. In addition, those grown under colored plastic films had significantly
A

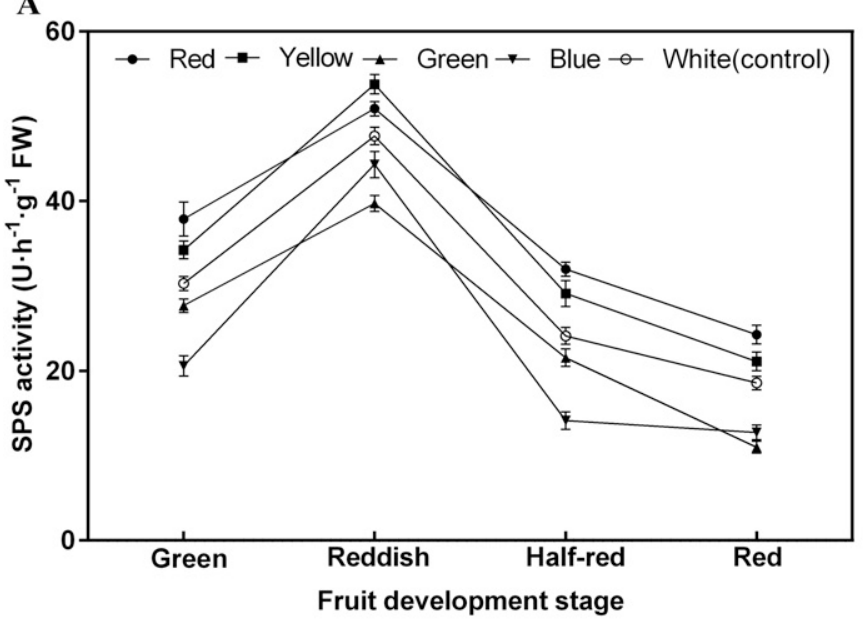

C

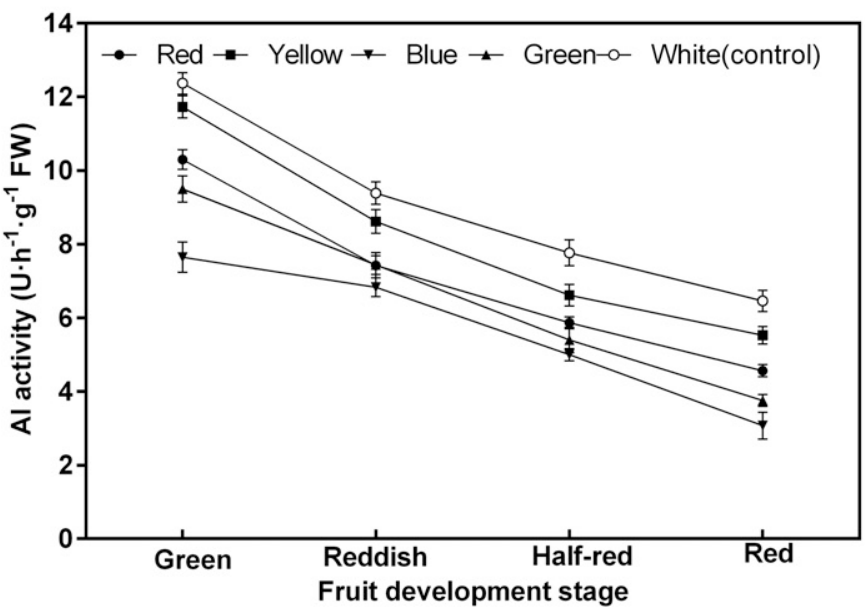

B

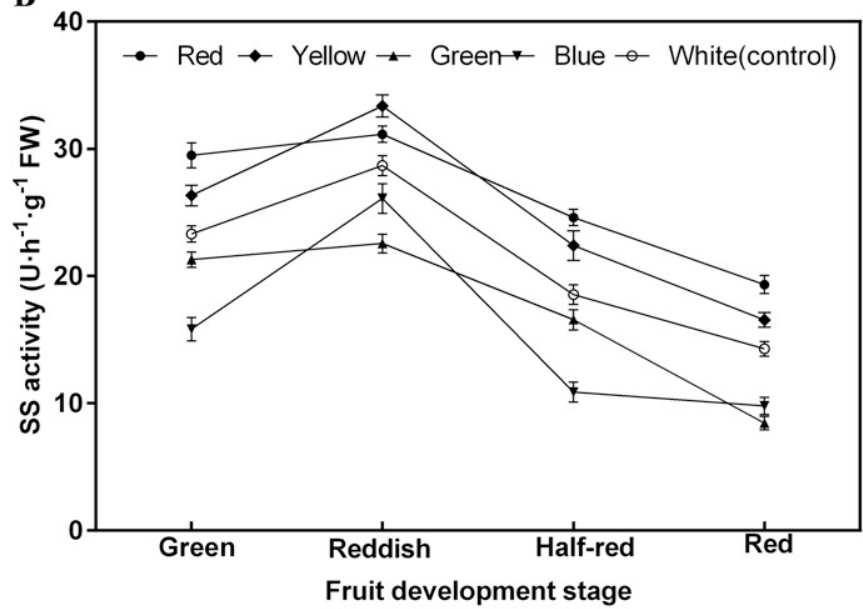

Fig. 3. Effect of colored plastic films on (A) sucrose phosphate synthase (SPS), (B) sucrose synthase (SS), and (C) acid invertase (AI) activity during strawberry fruit development. 

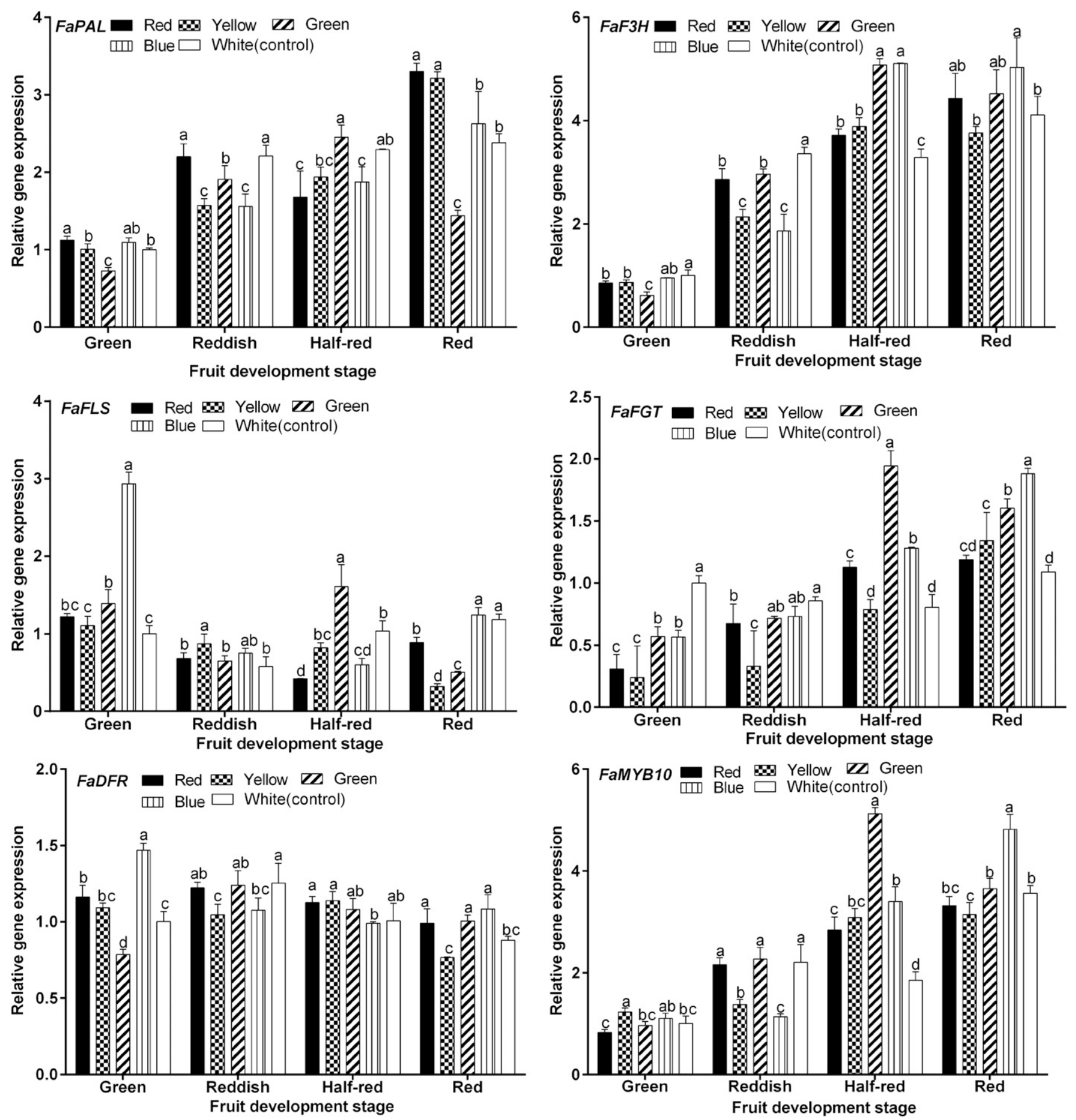

Fig. 4. Effect of colored plastic films on the expression of FaPAL, FaF3H, FaFLS, FaFGT, FaDFR, and FaMYB10 during strawberry fruit development.

increased $\mathrm{FaF} 3 \mathrm{H}$ transcription levels at the half-red stage compared with the fruits grown under the control plastic film. Compared with the fruits grown under the control plastic film, the $\mathrm{FaF} 3 \mathrm{H}$ expression in the fruits grown under blue plastic film had a higher level at the red stage, and there was no significance among red, yellow, green, and white plastic films at the red stage. The value of $\mathrm{FaF3H}$ expression was found with blue plastic film and was $22.44 \%$ higher than that obtained using the controls at the red stage. Previous reports showed that the strong upregulation of $F a F G T$ throughout fruit ripening leads to anthocyanin accumulation in strawberries (Almeida et al., 2007; Manning, 1998). Consistent with Almeida et al. (2007), the increasing trend has also been shown in the fruits grown under colored plastic films. However, the relative gene expression of FaFGT is around the value of 1 in white plastic film at the four stages.

The FaFLS expression fluctuated slightly during fruit development. Fruits grown under blue and green plastic films had increased FaFLS transcription levels at green and halfred stages, respectively. FaDFR results in the reduction of dihydroflavonols, the common precursors of flavonols and anthocyanins, to produce leucoanthocyanidins. FaDFR expression also showed slight fluctuations during fruit development. Therefore, colored plastic films had slight effects on FaDFR expression. The highest $F a D F R$ expression at the green stage was found with blue plastic film, whereas the lowest $F a D F R$ expression was found with green plastic film. Compared with control, fruits covered with yellow and blue plastic films had decreased the FaDFR level in the reddish stage, whereas no difference was found among fruits grown under red, green, and white plastic films. There was 
Table 5. Effect of colored plastic films on bioactive compounds and antioxidant capacity of ripe strawberry fruits.

\begin{tabular}{|c|c|c|c|c|c|c|}
\hline \multirow[b]{2}{*}{ Colored plastic film } & \multirow{2}{*}{$\begin{array}{c}\text { Total phenolics } \\
(\mu \mathrm{g} \text { gallic acid } / \mathrm{g} \mathrm{FW})\end{array}$} & \multirow{2}{*}{$\begin{array}{l}\text { Total flavonoids } \\
\text { ( } \mu \text { g rutin/g FW) }\end{array}$} & \multirow[b]{2}{*}{$\mathrm{TAC}\left(\mu \mathrm{g} \cdot \mathrm{g}^{-1} \mathrm{FW}\right)$} & \multicolumn{3}{|c|}{ Antioxidant capacity ( $\mu \mathrm{M}$ Trolox/g FW) } \\
\hline & & & & DPPH & ABTS & FRAP \\
\hline Red & $1,295.42 \pm 15.55 \mathrm{a}^{\mathrm{z}}$ & $695.54 \pm 32.79 a$ & $133.84 \pm 2.68 \mathrm{a}$ & $11.61 \pm 0.24 \mathrm{a}$ & $9.87 \pm 0.45 \mathrm{a}$ & $12.96 \pm 0.38 \mathrm{a}$ \\
\hline Yellow & $1,158.08 \pm 11.09 \mathrm{~b}$ & $570.23 \pm 15.82 b$ & $104.67 \pm 1.68 b$ & $11.30 \pm 0.28 b$ & $9.52 \pm 0.14 b$ & $12.87 \pm 0.59 \mathrm{~b}$ \\
\hline Green & $898.08 \pm 10.97 \mathrm{~d}$ & $464.77 \pm 24.59 \mathrm{c}$ & $54.97 \pm 0.53 \mathrm{e}$ & $9.44 \pm 0.19 \mathrm{~d}$ & $8.97 \pm 0.21 \mathrm{~d}$ & $9.85 \pm 0.39 \mathrm{~d}$ \\
\hline Blue & $978.54 \pm 8.51 \mathrm{~cd}$ & $552.00 \pm 60.49 \mathrm{~b}$ & $69.01 \pm 3.18 \mathrm{~d}$ & $9.85 \pm 0.17 \mathrm{~cd}$ & $9.45 \pm 0.33 \mathrm{bc}$ & $10.12 \pm 0.17 \mathrm{~d}$ \\
\hline White (control) & $1,052.31 \pm 10.92 \mathrm{c}$ & $554.77 \pm 23.94 \mathrm{~b}$ & $76.87 \pm 2.34 \mathrm{c}$ & $10.56 \pm 0.17 \mathrm{c}$ & $9.17 \pm 0.33 \mathrm{c}$ & $11.30 \pm 0.38 \mathrm{c}$ \\
\hline
\end{tabular}

${ }^{\mathrm{z}}$ Values in the same column followed by the different small letter are significantly different $(P<0.05)$.

$\mathrm{TAC}=$ total anthocyanin content; DPPH = 1,1-diphenyl-2-picrylhydrazyl; ABTS, 2,2' -azinobis-(3-ethylbenzothiazoline-6-sulfonate); FRAP = ferric reducing/ antioxidant power.

no difference in the FaDFR level at the halfred stage among all treatments. Compared with the controls, fruits grown under red, green, and blue plastic films had an increased FaDFR level at the red stage.

FaMYB10 plays a primary role in the regulation of anthocyanin biosynthesis and was identified as a receptacle-specific gene related to ripening (Medina-Puche et al., 2014). The expression of FaMYB10 gene correlates with fruit anthocyanin levels and showed an increasing trend during fruit development (Lin-Wang et al., 2010). Compared with the control plastic film, the colored plastic films had minor effects on the FaMYB10 expression in fruits at green and reddish stages. The expression of FaMYB 10 was significantly higher with colored plastic films than that with the control plastic film at the half-red stage. The FaMYB10 expression measured in the red stage was highest with blue plastic film. No significant difference of FaMYB10 expression was found in red, green, and white plastic film treatments at the red stage. At the red stage, the fruit grown under yellow plastic film had decreased FaMYB10 expression compared with the controls. In addition to light quality, light intensity has also been shown to positively affect FaMYB10 expression (Kadomura-Ishikawa et al., 2015; Lin-Wang et al., 2010). However, FaMYB10 only strongly affected the Cyanidin 3-glucoside content, and not the Pg3G content, in strawberry fruits (Kadomura-Ishikawa et al., 2015).

Overall, these results suggest that colored plastic films can regulate the expression of genes involved in the flavonoid biosynthesis pathway, especially FaPAL, FaF3H, FaFGT, and $F a M Y B 10$, at the half-red and red stages. The colored plastic films used in this study selectively filter the intercepted solar radiation. The changed light quality then induced the metabolism of fruit quality and bioactive compounds. The spectral manipulation was intended to specifically promote desired physiological responses (e.g., anthocyanin biosynthesis). Accordingly, the bioactive compounds of the fruits grown under red and yellow plastic films were higher than the controls. Postharvest strawberry treated with blue light can increase color index, total phenolic content, SUG, activities of antioxidant enzymes, and DPPH (Xu et al., 2014). These effects may be due to the activation of its related enzymes and genes, including $P A L, F L S, F 3 H, D F R$, and FGT.

Effect of colored plastic films on bioactive compounds and antioxidant capacity in ripened strawberry fruit. The colored plastic films exerted significant effects on phenolic, flavonoid, and TAC content (Table 5). The highest levels of bioactive compounds and antioxidant capacity were detected under the red plastic film. The total phenolic content was $23.10 \%$ higher with the red plastic film than with the control plastic film. Fruits grown under green plastic film had $14.66 \%$ lower phenolic content than those grown under the control plastic film. Although blue plastic film resulted in a lower phenolic content than the control plastic film, the difference between the two plastic films was nonsignificant. The total flavonoid content was $25.37 \%$ higher with the red plastic film than with the control plastic film. The total flavonoid content of the fruits grown under yellow and blue plastic films exhibited no significant differences compared with that of the controls, whereas the green plastic film resulted in a value that was $16.23 \%$ lower than that of the controls. Compared with the control plastic film, the red and yellow plastic films led to significantly increased TAC, whereas the green and blue plastic films led to decreased TAC. The TAC content of the fruit grown under red and yellow plastic films increased by $74.11 \%$ and $36.17 \%$, respectively, when compared with those grown under the control plastic film. The TAC content of the fruit grown under green and blue plastic films decreased by $28.49 \%$ and $10.22 \%$, respectively, compared with those grown under the control plastic film.

Consistent with previous studies, flavonoids are the main polyphenol compounds in strawberry fruits, and their biosynthetic pathway has been extensively studied (Lin-Wang et al., 2010; Medina-Puche et al., 2014). A previous study showed that red plastic film can activate the related enzymes (PAL, cinnamate-4-hydroxylase, 4-coumarate-CoA ligase, chalcone isomerase, chalcone synthase, and anthocyanidin synthase) and affect the expression of transcription factor genes (MYB10, MYB1, and MYB5) in the flavonoid pathway (Miao et al., 2016). The colored plastic films used in this study may have the capacity to selectively filter the intercepted solar radiation, and then the changed light quality induced the metabolism of fruit quality and bioactive compounds.

The DPPH, FRAP, and ABTS assays are the most commonly used methods to determine antioxidant capacity in vitro (Mishra et al., 2015; Wojdyło et al., 2014; Xu et al., 2014). The antioxidant evaluations using the DPPH, ABTS, and FRAP methods in the present study are shown in Table 5 and demonstrate similar trends. The antioxidant capacities were highest in the fruits grown under the red plastic film followed by those grown under the yellow plastic film.

According to the correlation coefficients for relationships between bioactive compounds and antioxidant capacity, positive and significant correlations of the total phenolics with flavonoids, TAC, DPPH, ABTS, and FRAP were detected (Table 6). Fruits with the highest phenolic content (the fruits grown under the red plastic film) had the highest antioxidant capacity, whereas the fruit extracts characterized by low total phenolic levels (the fruits grown under green and blue plastic films) exhibited poor antioxidant capacity. Consistent with this result, previous studies have reported similar linear relationships between antioxidant capacity and phenolic content (Mishra et al., 2015; Wojdyło et al., 2014).

The published reports indicated that the total phenolic content plays a vital role in antioxidant capacity and that the type of phenolic compounds is critical (Toydemir et al., 2013; Wojdyło et al., 2014). The present results suggest that the antioxidant capacity of strawberry fruit is highly related to the presence of anthocyanins. Positive and significant correlations $(P<0.05)$ of TAC with flavonoids $(r=0.937)$, DPPH $(r=0.956)$, ABTS $(r=0.908)$, and FRAP $(r=0.934)$ were detected. However, no

Table 6. Pearson's correlation coefficients $(r)$ between bioactive compounds and antioxidant capacity.

\begin{tabular}{llllll}
\hline & Phenolics & Flavonoids & DPPH & ABTS & FRAP \\
\hline Flavonoids & $0.942^{* \mathrm{z}}$ & & & & \\
DPPH & $0.975^{* *}$ & 0.86 & & & \\
ABTS & $0.887^{*}$ & $0.937^{*}$ & 0.808 & 0.757 & \\
FRAP & $0.948^{*}$ & 0.79 & $0.990^{* *}$ & $0.908^{*}$ & $0.934^{*}$
\end{tabular}

${ }^{\mathrm{z}}$ Single and double asterisks indicate significant differences at $P<0.05$ and $P<0.01$.

$\mathrm{DPPH}=$ 1,1-diphenyl-2-picrylhydrazyl; ABTS = 2,2' -azinobis-(3-ethylbenzothiazoline-6-sulfonate); FRAP $=$ ferric reducing/antioxidant power. 
correlation was observed between flavonoids and DPPH or FRAP because anthocyanins are the major antioxidants in ripened fruit. The correlations among DPPH, ABTS, and FRAP assays were high and positive, ranging from 0.757 to 0.990 ; the strongest correlation was between FRAP and DPPH $(r=0.990, P<$ 0.01 ), and the weakest correlation was between FRAP and ABTS ( $r=0.757)$. Strong correlations among these three variables have also been found in other crops (Thaipong et al., 2006).

Moreover, colored plastic film treatments significantly affected the expression of sugar accumulation-related genes, suggesting that the effects on fruit quality, bioactive compounds, and antioxidant capacity resulted from the activation of related genes. Photosynthates are the primary source of sugar in fruit (Giovannoni, 2004; Zhang and Chen, 2007). Part of the photosynthates in fruit had been turned into glucose and participated in the shikimic acid metabolism pathway (Mobin et al., 2015). Phosphoenolpyruvate and erythrose-4- phosphate can be derived by the glycolytic and the pentose phosphate pathway. And then, shikimic acid can be biosynthesized with the help of many enzymes (Mobin et al., 2015). The chorismate derived from the shikimic acid metabolism pathway is the synthesized substrate of phenylalanine (Mobin et al., 2015). Bioactive compounds can be biosynthesized via the phenylpropanoid pathway and the flavonoid biosynthetic pathway (Medina-Puche et al., 2014). In the present study, only strawberry fruits had been grown under colored plastic films with identical light intensity. The growth environment of the fruits grown under plastic films mainly differs in light quality and temperature. A previous study showed that light can affect fruit quality, and the physiological response to a light stimulus is located in the fruit (Zoratti et al., 2014). Plants subjected to reduced light levels and temperature conditions often respond with the accumulation of secondary metabolites, including bioactive compounds (Susanne et al., 2016). These metabolites play a role in adaptation to the less favorable environment and in overcoming stress conditions. In the present study, all the fruits grown under colored plastic films had a higher temperature than the controls. A report had showed that higher temperature mainly increased the hydroxycinnamic acid derivative, disinapoyl-gentiobiose (Susanne et al., 2016). However, this effect was not fully reflected in this study. This may attribute to the difference of light quality and the radiation environment around the fruit that had been altered.

\section{Conclusions}

The colored plastic films had significant influences on the fruit quality, content of bioactive compounds, and antioxidant capacity in the attached strawberry plants. Fruits grown under blue plastic film had increased sugar content compared with those grown in the control plastic film, including sucrose, glucose, and fructose. The ACID in fruits grown under red, blue, and green plastic films had significantly decreased compared with in the fruits grown under control, mainly because the citric content decreased. Treatment with the colored plastic films decreased the malic acid content, except for the yellow plastic film. Fruits grown under blue plastic film had the highest SUG/ACID ratio because they exhibited the highest sugar content and low acid content. The red and green plastic films also significantly increased the SUG/ ACID ratio. The red plastic film increased the bioactive compound content and resulted in the highest antioxidant capacity. The expression levels of sugar and acid accumulationrelated genes and flavonoid genes were significantly affected by the colored plastic films, suggesting that the effects on fruit quality, bioactive compounds, and antioxidant capacity resulted from the activation of related genes. These enhancements of fruit quality, bioactive compounds, and antioxidant capacity are achievable because of the reflected light quality.

\section{Literature Cited}

Almeida, J.R., E. D'Amico, A. Preuss, F. Carbone, C.H. de Vos, B. Deiml, F. Mourgues, G. Perrotta, T.C. Fischer, A.G. Bovy, S. Martens, and C. Rosati. 2007. Characterization of major enzymes and genes involved in flavonoid and proanthocyanidin biosynthesis during fruit development in strawberry (Fragaria $\times$ ananassa). Arch. Biochem. Biophys. 465:61-71.

Amarante, C., N.H. Banks, and S. Max. 2002. Effect of preharvest bagging on fruit quality and postharvest physiology of pears (Pyrus communis). New. Zeal. J. Crop Hortic. 30:99107.

Amil-Ruiz, F., J. Garrido-Gala, R. Blanco-Portales, K.M. Folta, J. Muñoz-Blanco, and J.L. Caballero. 2013. Identification and validation of reference genes for transcript normalization in strawberry (Fragaria $\times$ ananassa) defense responses. PLoS One 8:E70603.

Anttonen, M.J., K.I. Hoppula, R. Nestby, M.J. Verheul, and R.O. Karjalainen. 2006. Influence of fertilization, mulch color, early forcing, fruit order, planting date, shading, growing environment, and genotype on the contents of selected phenolics in strawberry (Fragaria xananassa Duch.) fruits. J. Agr. Food Chem. 54:2614 2620.

Ban, Y., S. Kondo, B.E. Ubi, C. Honda, H. Bessho, and T. Moriguchi. 2009. UDP-sugar biosynthetic pathway: Contribution to cyanidin 3galactoside biosynthesis in apple skin. Planta 230:871-881

Basson, C.E., J.H. Groenewald, J. Kossmann, C. Cronjé, and R. Bauer. 2010. Sugar and acidrelated quality attributes and enzyme activities in strawberry fruits: Invertase is the main sucrose hydrolysing enzyme. Food Chem. 121:1156-1162.

Basu, A., A. Nguyen, N.M. Betts, and T.J. Lyons. 2014. Strawberry as a functional food: An evidence-based review. Crit. Rev. Food Sci. Nutr. 54:790-806.

Casierra-Posada, F., E. Fonseca, and G. Vaughan. 2011. Fruit quality in strawberry (Fragaria sp.) grown on colored plastic mulch. Agron. Colomb. 29:407-413.
Chang, L., Z. Zhang, H. Yang, H. Li, and H. Dai. 2007. Detection of strawberry RNA and DNA viruses by RT-PCR using total nucleic acid as a template. J. Phytopathol. 155:431-436.

Ding, L., D. Hofius, M.R. Hajirezaei, A.R. Fernie, F. Börnke, and U. Sonnewald. 2007. Functional analysis of the essential bifunctional tobacco enzyme 3-dehydroquinate dehydratase/shikimate dehydrogenase in transgenic tobacco plants. J. Expt. Bot. 58:2053-2067.

Giampieri, F., J.M. Alvarez-Suarez, and M. Battino. 2014. Strawberry and human health: Effects beyond antioxidant activity. J. Agr. Food Chem. 62:3867-3876.

Giovannoni, J.J. 2004. Genetic regulation of fruit development and ripening. Plant Cell 16:S170 S180.

Hemming, S. 2009. Use of natural and artificial light in horticulture - Interaction of plant and technology. Acta Hort. 907:2079-2087.

Hemming, S., E.A. van Os, J. Hemming, and J.A. Dieleman. 2006. The effect of new developed fluorescent greenhouse films on the growth of Fragaria Xananassa 'Elsanta'. Eur. J. Hort. Sci. 71(4):145-154.

Hudina, M. and F. Stampar. 2011. Effect of fruit bagging on quality of 'Conference' pear (Pyrus communis L.). Eur. J. Hort. Sci. 76:176-181.

Hulme, A.C. 1958. Quinic and shikimic acids in fruits. Qual. Plant. Mater. Veg. 3-4:468-473.

Isherwood, F.A. and R.R. Selvendran. 1970. A note of the occurrence of nucleotides in strawberry leaves. Phytochemistry 9:2265-2269.

Jaakola, L. 2013. New insights into the regulation of anthocyanin biosynthesis in fruits. Trends Plant Sci. 18:477-483.

Jia, Z., M. Tang, and J. Wu. 1999. The determination of flavonoid contents in mulberry and their scavenging effects on superoxide radicals. Food Chem. 64:555-559.

Kadomura-Ishikawa, Y., K. Miyawaki, A. Takahashi, T. Masuda, and S. Noji. 2015. Light and abscisic acid independently regulated FaMYB10 in Fragaria Xananassa fruit. Planta 241:953965.

Kasperbauer, M.J., J.H. Loughrin, and S.Y. Wang. 2001. Light reflected from red mulch to ripening strawberries affects aroma, sugar and organic acid concentrations. Photochem. Photobiol. 74:103-107.

Lin-Wang, K., K. Bolitho, K. Grafton, A. Kortstee, S. Karunairetnam, T. McGhie, R. Espley, R. Hellens, and A. Allan. 2010. An R2R3 MYB transcription factor associated with regulation of the anthocyanin biosynthetic pathway in Rosaceae. BMC Plant Biol. 10:549-553.

Livak, K.J. and T.D. Schmittgen. 2001. Analysis of relative gene expression data using real-time quantitative PCR and the $2^{-\triangle \Delta C T}$ method. Methods 25:402-408.

Mahmood, T., F. Anwar, M. Abbas, M.C. Boyce, and N. Saari. 2012. Compositional variation in sugars and organic acids at different maturity stages in selected small fruits from Pakistan Intl. J. Mol. Sci. 13:1380-1392.

Manning, K. 1998. Isolation of a set of ripeningrelated genes from strawberry: Their identification and possible relationship to fruit quality traits. Planta 205:622-631.

Medina-Puche, L., G. Cumplido-Laso, F. Amil-Ruiz, T. Hoffmann, L. Ring, A. Rodríguez-Franco, J. Caballero, W. Schwab, J. Muñoz-Blanco, and R. Blanco-Portales. 2014. MYB10 plays a major role in the regulation of flavonoid/phenylpropanoid metabolism during ripening of Fragaria $\times$ ananassa fruits. J. Expt. Bot. 65:401-417.

Mi, G., L. Liu, B. Jin, Z. Zhang, and H. Ren. 2011. Influence of low light on net photosynthesis 
rate and activities of enzymes related to sucrose metabolism in cucumber seedlings. Acta Agriculturae Boreali-Sinica 26(1):146-150.

Miao, L., Y. Zhang, X. Yang, J. Xiao, H. Zhang, Z. Zhang, Y. Wang, and G. Jiang. 2016. Colored light-quality selective plastic films affect anthocyanin content, enzyme activities, and the expression of flavonoid genes in strawberry (Fragaria ×ananassa) fruit. Food Chem. 207:93-100.

Miron, D. and A. Schaffer. 1991. Sucrose phosphate synthase, sucrose synthase, and invertase activities in developing fruit of Lycopersicon esculentum Mill. and the sucrose accumulating Lycopersicon hirsutum Humb. and Bonpl. Plant Physiol. 95(2):623-627.

Mishra, V., C. Shah, N. Mokashe, R. Chavan, H. Yadav, and J. Prajapati. 2015. Probiotics as potential antioxidants: A systematic review. J. Agr. Food Chem. 63:3615-3626.

Mobin, M., C.H. Wu, R.K. Tewari, and K.Y. Paek. 2015. Studies on the glyphosate-induced amino acid starvation and addition of precursors on caffeic acid accumulation and profiles in adventitious roots of Echinacea purpurea (L.) Moench. Plant Cell Tissue Organ Cult. 120(1): 291-301.

Ogiwara, I., S. Harada, Y. Togetani, S. Suzuki, N. Nishikubo, and Y. Katayama. 2005. Changes in sugar content and in activities of invertase, sucrose synthase and sucrose phosphate synthase during ripening stage of strawberry fruit. J. Jpn. Soc. Hort. Sci. 74:179.

Pombo, M.A., G.A. Martínez, and P.M. Civello. 2011. Cloning of FaPAL6 gene from strawberry fruit and characterization of its expression and enzymatic activity in two cultivars with different anthocyanin accumulation. Plant Sci. 181:111-118.

Samuolienè, G., A. Brazaitytè, A. Urbonavičiūtè, G. Šabajeviene, and P. Duchovskis. 2010. The effect of red and blue light component on the growth and development of frigo strawberries. Zemdirbyste 97(2):99-104.

Sharma, R.R., M.J. Jhalegar, and S.V.R. Reddy. 2014. Pre-harvest fruit bagging: A useful approach for plant protection and improved post-harvest fruit quality - A review. J. Hort. Sci. Biotechnol. 89:101-113.

Shiukhy, S., M. Raeini-Sarjaz, and V. Chalavi. 2015. Colored plastic mulch microclimates affect strawberry fruit yield and quality. Intl. J. Biometeorol. 59:1061-1066.

Shui, G. and L.P. Leong. 2002. Separation and determination of organic acids and phenolic compounds in fruit juices and drinks by high-performance liquid chromatography. J. Chromatogr. A 977(1):89-96.

Silva, F.L.d., M.T. Escribano-Bailón, J.J.P. Alonso, J.C. Rivas-Gonzalo, and C. SantosBuelga. 2007. Anthocyanin pigments in strawberry. Lebensm. Wiss. Technol. 40:374-382.

Singleton, V.L. and J.A. Rossi. 1965. Colorimetry of total phenolics with phosphomolybdicphosphotungstic acid reagents. Amer. J. Enol. Viticult. 16:144-158.

Susanne, N., K. Angelika, and Z. Rita. 2016. Influence of light and temperature on gene expression leading to accumulation of specific flavonol glycosides and hydroxycinnamic acid derivatives in kale (Brassica oleracea var. sabellica). Front. Plant Sci. 7(222):326.

Swain, T. and W.E. Hillis. 1959. The phenolic constituents of Prunus domestica. I. The quantitative analysis of phenolic constituents. J. Sci. Food Agr. 10:63-68.

Tang, Q.Y. and C.X. Zhang. 2012. Data processing system (DPS) software with experimental design, statistical analysis and data mining developed for use in entomological research. Insect Sci. 20:254-260.

Thaipong, K., U. Boonprakob, K. Crosby, L. CisnerosZevallos, and D.H. Byrne. 2006. Comparison of ABTS, DPPH, FRAP, and ORAC assays for estimating antioxidant activity from guava fruit extracts. J. Food Compos. Anal. 19:669-675.

Tian, L., H.F. Jia, C.L. Li, P.G. Fan, Y. Xing, and Y.Y. Shen. 2012. Sucrose accumulation during grape berry and strawberry fruit ripening is controlled predominantly by sucrose synthase activity. J. Hort. Sci. Biotechnol. 87:661-667.
Toydemir, G., E. Capanoglu, M.V.G. Roldan, R.C.H.D. Vos, D. Boyacioglu, R.D. Hall, and J. Beekwilder. 2013. Industrial processing effects on phenolic compounds in sour cherry (Prunus cerasus L.) fruit. Food Res. Intl. 53:218-225.

Wojdyło, A., P. Nowicka, P. Laskowski, and J. Oszmiański. 2014. Evaluation of sour cherry (Prunus cerasus L.) fruits for their polyphenol content, antioxidant properties, and nutritional components. J. Agr. Food Chem. 62:1233212345.

Xu, F., L. Shi, W. Chen, S. Cao, X. Su, and Z. Yang. 2014. Effect of blue light treatment on fruit quality, antioxidant enzymes and radicalscavenging activity in strawberry fruit. Sci. Hort. 175:181-186.

Xu, H., J. Chen, and M. Xie. 2010. Effect of different light transmittance paper bags on fruit quality and antioxidant capacity in loquat. J. Sci. Food Agr. 90:1783-1788.

Xu, K., Y. Guo, S. Zhang, W. Dai, and Q. Fu. 2007. Effect of light quality on the fruit quality of 'Toyonoka' strawberry (Fragaria ×ananassa Duch.). Acta Horticulturae Sinica 34(3):585590.

Zhang, S. and K. Chen. 2007. Molecular physiology of fruit quality development and regulation. China Agriculture Press, Beijing, China.

Zhao, C., L. Hua, X. Liu, Y. Li, Y. Shen, and J. Guo. 2017. Sucrose synthase FaSS1 plays an important role in the regulation of strawberry fruit ripening. Plant Growth Regulat. 81 (1):175-181.

Zoratti, L., L. Jaakola, H. Häggman, and L. Giongo. 2015. Modification of sunlight radiation through colored photo-selective nets affects anthocyanin profile in Vaccinium spp. berries. PLoS One 10(8):e0135935.

Zoratti, L., K. Karppinen, A. Luengo Escobar, H. Häggman, and L. Jaakola. 2014. Lightcontrolled flavonoid biosynthesis in fruits. Front. Plant Sci. 5:1-6. 